\title{
Canadian Adult Asthma Update 2008 key messages: A focus on translating knowledge into action in primary care
}

\author{
Andrew Mclvor MD MSC FRCPC ${ }^{1}$, Rick Hodder MD FRCPC ${ }^{2}$
}

$\mathrm{T}^{\mathrm{h}}$ he Asthma Committee of the Canadian Thoracic Society (CTS) is currently completing a case-based series to illustrate 'key messages' for adult asthma diagnosis and management in 2008. This initiative will include a key points document directed toward primary care physicians and will be accompanied by the distribution of a number of practical tools designed to help facilitate more widespread implementation of the guideline recommendations in daily clinical practice. The CTS Asthma Committee believes that focusing on knowledge translation and partnering with family doctors, certified asthma educators, pharmacists and allied health care professionals to encourage the application of a chronic disease management model to asthma will lead to improvements in asthma control and thereby a reduction in exacerbations and mortality.

The first asthma guidelines were produced by the CTS' multidisciplinary Asthma Committee approximately two decades ago (1). Initially created via a process that included a consensus meeting, subsequent revisions and updates of the guidelines have involved extensive critical appraisal of emerging medical literature, thereby ensuring the creation of relevant, evidence-based reports $(2,3)$. However, despite the creation and dissemination of these guidelines, as well as various concomitant supportive initiatives, comprehensive patient and physician surveys continue to document poor asthma control in Canada. The most recent Canadian study of this problem, the Personal Practice Assessment Programme, surveyed more than 350 Canadian primary care physicians and more than 10,000 patients with asthma (4). Once again, a high degree of poor asthma care was observed, with $59 \%$ of patients manifesting uncontrolled asthma despite physician care and guidance.

Access to an excellent and constantly evolving pharmacological armamentarium and modern management strategies should ensure that the vast majority of Canadians with asthma expect, demand and achieve control over asthma. It is therefore disheartening that clinicians in Canada do not appear to be successfully integrating guideline-based recommendations into clinical care, such as scheduling regular reassessments to evaluate the effectiveness of their asthma management plans and, when indicated, identifying potential barriers to achieving good asthma control and then implementing successful solutions. Other key recommendations that are commonly overlooked include attention to environmental control, routine creation of written action plans to deal with worsening asthma, and the need to take into account health literacy when educating patients (5).
The CTS Asthma Committee has therefore re-examined the way in which it has been producing and disseminating guidelines. It has concluded that significantly greater effort should be applied to knowledge translation, rather than focusing almost exclusively on evidence review and guideline production (6).

Recent experience supports the effectiveness of knowledge translation strategies on asthma care. For example, following a report that asthma hospitalization rates varied approximately threefold among centres across Ontario (7), the Ontario Ministry of Health and Long-Term Care asked the Ontario Lung Association to develop a targeted continuing medical education program on asthma management. The result was the Primary Care Asthma Program, which involved 137 workshops attended by 2133 people - of whom one-half were physicians - focusing on implementation of the Canadian asthma guidelines in primary care (8). Follow-up surveys of participants indicated that they were adhering more closely to recommended asthma care guidelines, including using more evidence-based prescribing, spirometries and asthma action plans.

In another Ontario initiative to promote the use of guidelinesupported practices for acute asthma care, the Ontario Ministry of Health and Long-Term Care and the Ontario Lung Association, with CTS support, have recently developed an updated evidence-based algorithm for emergency department assessment and management of acute asthma. This algorithm, with information on how to implement it, will soon be published and disseminated. It will be accompanied by a poster for display in emergency departments, as well as a pocket-sized summary of best practices for the assessment and management of acute asthma.

A third practical example of how knowledge translation can improve asthma care in primary practice is the 'paper-stamp checklist tool' recently developed and tested by Dr Paolo Renzi from Montreal, Quebec (9). Dr Renzi documented that use of this simple tool during clinic visits not only increased physicians' knowledge of Canadian asthma guidelines, but more importantly, it was associated with reduced emergency department visits and hospitalizations for patients over a one-year follow-up period (9). The checklist tool is currently being disseminated across the country, starting with 1200 Quebec physicians and is just one of a series of similar instruments developed and evaluated recently in Quebec (10).

To determine how to best apply this shift in focus to knowledge translation for asthma, the CTS Asthma Committee

${ }^{1}$ McMaster University, Hamilton; ${ }^{2}$ University of Ottawa, Ottawa, Ontario

Correspondence: Dr Andrew McIvor, McMaster University, Firestone Institute for Respiratory Health, St Joseph's Healthcare,

50 Charlton Avenue East, Room T2127, Hamilton, Ontario L8N 4A6. E-mail amcivor@stjosham.on.ca 
recently hosted a workshop on guideline dissemination and implementation. Leading respirologists from Canada, the United States and Europe attended, as did certified asthma educators, and experts in knowledge translation from the pharmaceutical industry and from Health Canada. The two-day, interactive workshop resulted in a report entitled "Implementing practice guidelines: A workshop on guidelines dissemination and implementation with a focus on asthma and COPD" (11) that was published as a supplement to the Canadian Respiratory Journal. A follow-up workshop on Canadian respiratory guidelines implementation - funded by the CTS, the Canadian Institutes of Health Research and AllerGen - took place in April 2007.

The 2008 key messages of the CTS Asthma Committee have thus been developed with emphasis on knowledge translation as a more practical means to facilitate improved asthma control and hence optimize patient outcomes. In addition, the new messages will be relatively short and will focus on a discrete number of topics relevant to primary care management of asthma. Concomitantly, a series of case-based modules illustrating specific aspects of asthma management - for example, office-based management of asthma exacerbations and the role of allergy in asthma - has been developed for primary care physicians. The CTS Professional Development Committee is also creating a similar set of primary care cases with web-based access, to be launched in June 2008 at the first annual Canadian Respiratory Conference in Montreal.

The goal of these and other targeted efforts by the CTS is to help make implementation of the guideline recommendations more practical and user-friendly. In so doing, we hope the result will be improved asthma care, which we believe will in turn lead to a significant reduction in the burden currently imposed by asthma on the Canadian society.

\section{REFERENCES}

1. Hargreave FE, Dolovich J, Newhouse MT. The assessment and treatment of asthma: A conference report. J Allergy Clin Immunol 1990;85:1098-111.

2. Boulet LP, Becker A, Bérubé D, Beveridge R, Ernst P. Canadian Asthma Consensus Report, 1999. Canadian Asthma Consensus Group. CMAJ 1999;161(11 Suppl):S1-61.

3. Lemière $C$, Bai $T$, Balter $M$, et al. Adult Asthma Consensus Guidelines Update 2003. Can Respir J 2004;11(Suppl A):9A-18A.

4. Chapman KR, Boulet LP, Rea RM, Franssen E. Suboptimal asthma control: Prevalence, detection and consequences in general practice. Eur Respir J 2008;31:320-5.

5. Poureslami IM, Rootman I, Balka E, Devarakonda R, Hatch J, Fitzgerald JM. A systematic review of asthma and health literacy: A cultural-ethnic perspective in Canada. MedGenMed 2007;9:40.

6. Graham ID, Logan J, Harrison MB, et al. Lost in knowledge translation: Time for a map? J Contin Educ Health Prof 2006;26:13-24.

7. Lougheed MD, Garvey N, Chapman KR, et al. The Ontario Asthma Regional Variation Study: Emergency department visit rates and the relation to hospitalization rates. Chest 2006;129:909-17.

8. Lougheed MD, Moosa D, Finlayson S, et al. Impacts of a provincial asthma guidelines continuing medical education project: The Ontario Asthma Plan of Action's Provider Education in Asthma Care Project. Can Respir J 2007;14:111-7.

9. Renzi PM, Ghezzo H, Goulet S, Dorval E, Thivierge RL. Paper stamp checklist tool enhances asthma guidelines knowledge and implementation by primary care physicians. Can Respir J 2006;13:193-7. (Erratum in 2006;13:279).

10. Boulet LP, Dorval E, Labrecque M, Turgeon M, Montague T, Thivierge RL. Towards Excellence in Asthma Management (TEAM). Final report of an 8-year program aimed at reducing care gaps in asthma management in Quebec. Can Respir J 2008. (InPress)

11. Boulet LP, Becker A, Bowie D, Hernandez P, McIvor A, Rouleau M. Implementing practice guidelines: A workshop on guidelines dissemination and implementation with a focus on asthma and COPD. Can Respir J 2006;13(Suppl A):5A-47A. 


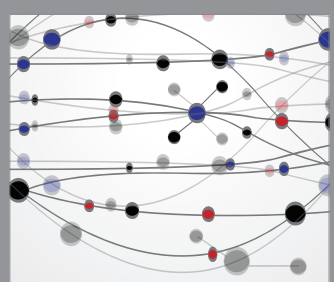

The Scientific World Journal
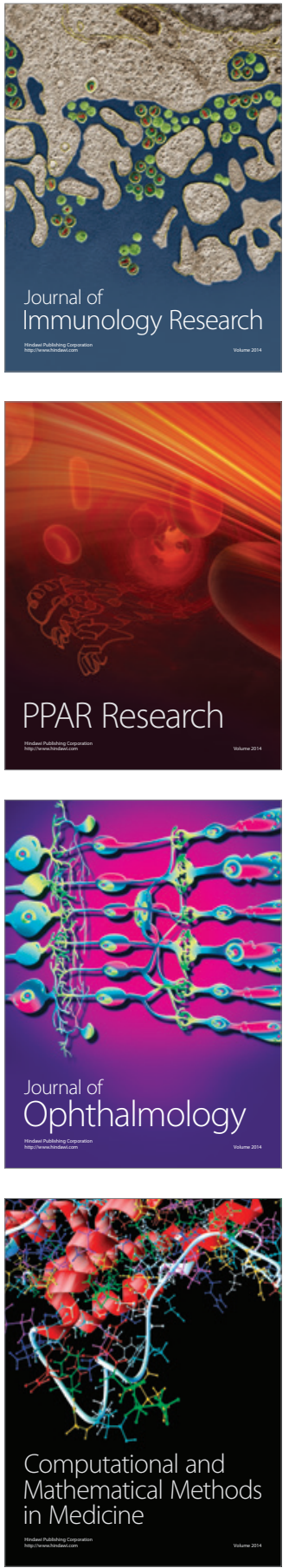

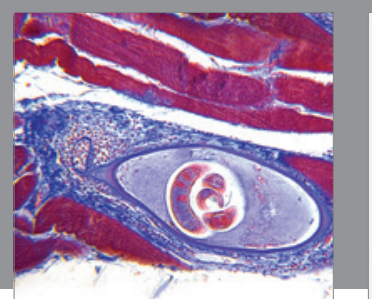

Gastroenterology Research and Practice

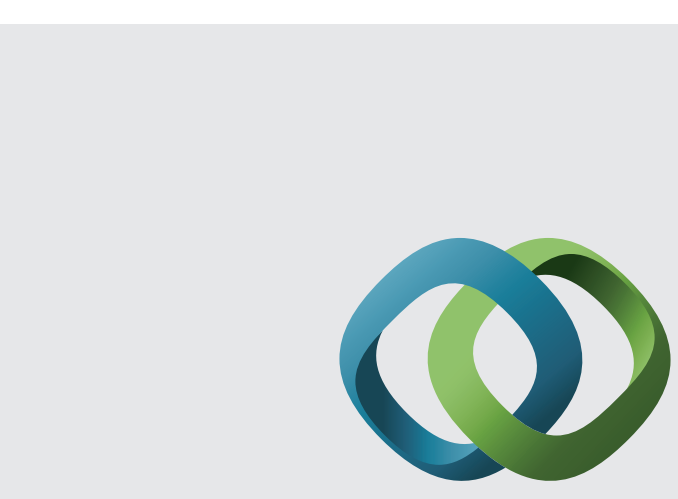

\section{Hindawi}

Submit your manuscripts at

http://www.hindawi.com
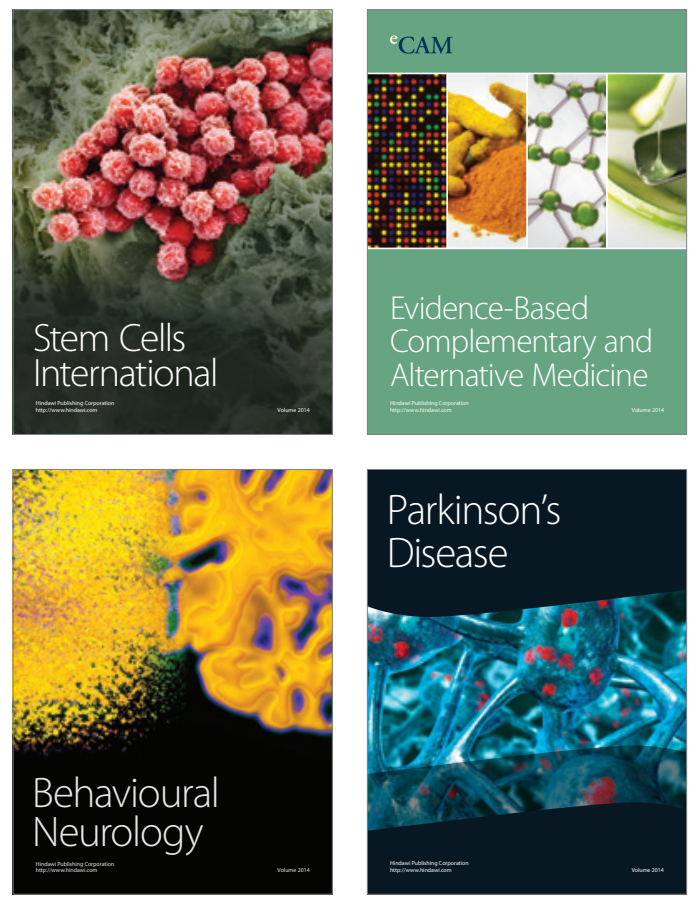
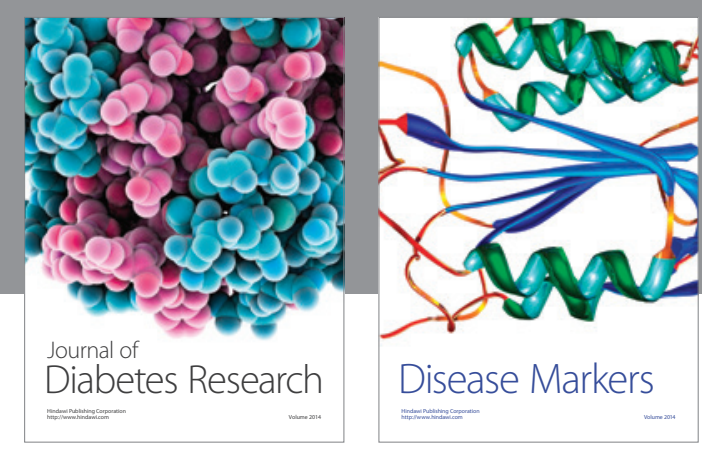

Disease Markers
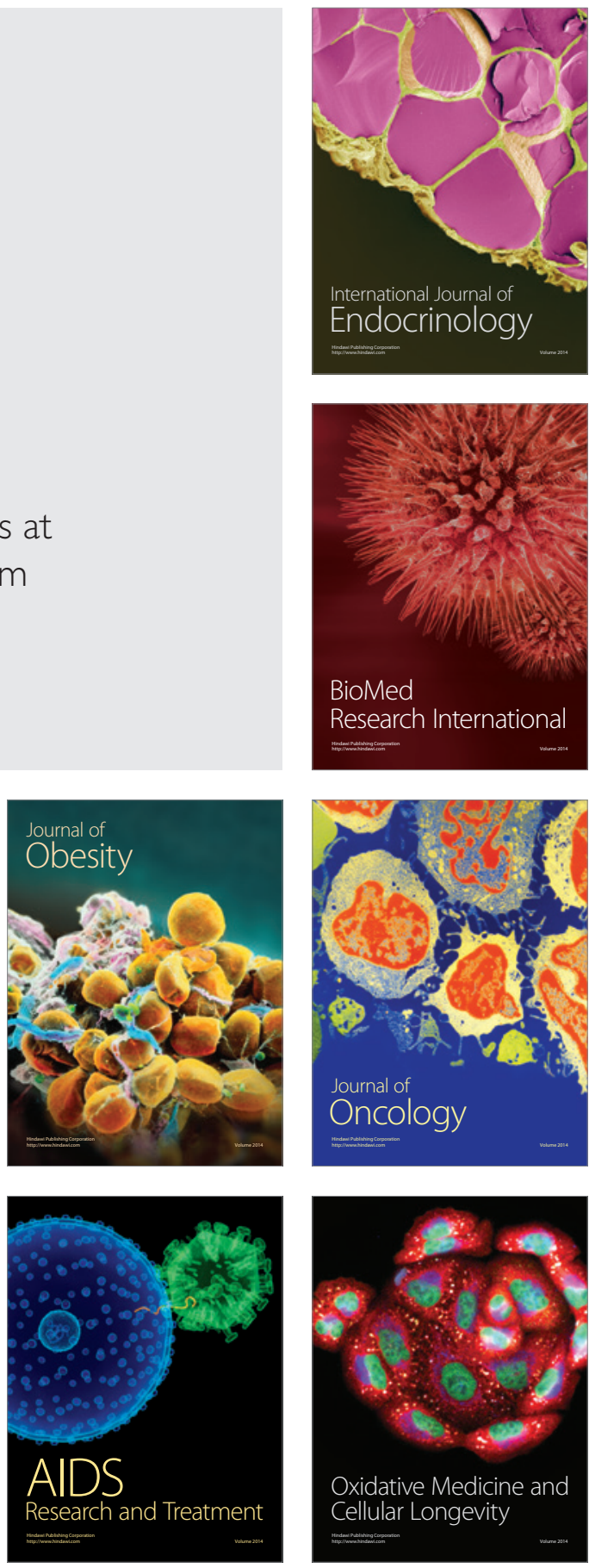